\title{
Common Hazards to Consider During Manufacturing of Feeds for Horses ${ }^{1}$
}

\author{
Jason M. Scheffler, Taylor N. Langford, Carissa Wickens, and Lori Warren²
}

\section{Introduction}

The Food Safety Modernization Act (FSMA) was signed into law in January of 2011. This law attempts to shift the focus of food safety from reacting to foodborne outbreaks to preventing them from occurring. The law stipulates that complying facilities that manufacture, process, pack, or hold food (hereafter referred to as feed) ingredients for animals implement a Hazard Analysis and Risk-Based Preventive Controls food safety plan (Scheffler and Carr 2016). This food safety plan has similarities to the Hazard Analysis and Critical Control Points (HACCP) commonly used in human foods such as meat, seafood, and juice, but it may be unfamiliar to facilities producing feed for horses. More information on compliance requirements and the general structure of an animal food safety plan can be found at http://edis.ifas.ufl.edu/an330.

A hazard analysis is a core component of a food safety plan. A thorough hazard analysis should identify potential hazards and their appropriate frequencies and severities in order to determine methods of prevention. In many cases, hazards can be controlled with written Current Good Manufacturing Practices (CGMPs) and Standard Operating Procedures (SOPs). However, in some cases, hazards exist which require more robust preventive controls. Determination of whether a hazard requires a preventative control depends on the frequency and severity of the hazard, which can vary by facility and species being fed. This document provides a list of common hazards to consider in the production and distribution of horse feeds. This is not a comprehensive list of hazards. A thorough hazard analysis is required to identify hazards for each facility.

\section{What are the types of common hazards in horse feeds?}

Hazards can be divided into three major categories: biological, chemical (including radiological), and physical. A hazard analysis must consider the possible hazards relevant to the facility, the feed being produced, the animals consuming the feed, and people handling the feed. Thus, each facility must conduct its own hazard analysis, even if multiple facilities are under the same ownership and making similar feed. Conducting a hazard analysis should be the first step in writing your food safety plan. For more information about writing a food safety plan or conducting a hazard analysis, refer to http://edis.ifas.ufl.edu/an330.

\section{What are common biological hazards to consider?}

The biological hazards in horse feeds are relatively few compared to those in human and pet food. In most cases, the pathogens of concern for horses are not derived from feed, but through other routes of infection.

1. This document is AN344, one of a series of the Department of Animal Sciences, UF/IFAS Extension. Original publication date June 2018. Visit the EDIS website at http://edis.ifas.ufl.edu.

2. Jason M. Scheffler, assistant professor; Taylor N. Langford, graduate student; Carissa Wickens, assistant professor; and Lori Warren, associate professor, Department of Animal Sciences; UF/IFAS Extension, Gainesville, FL 32611. 
Salmonella is the most likely biological hazard targeted for prevention in horse feeds because it poses the most significant risk to humans and horses. Humans are susceptible to a wide range of Salmonella enterica serovars (abbreviated as $S$. [Serovar]). However, the main species and serotypes of concern in horses are $S$. Abortusequi (FDA 2013), S. Typhimurium, and S. Agona (Beaudoin and Valberg 2017). Salmonella Abortusequi is known to cause abortions in horses. However, prevalence in feed is rare; it is not one of the 25 most common Salmonella species in animal feed (Li et al. 2012). Salmonella Typhimurium and $S$. Agona may cause severe diarrhea and can progress to septicemia in foals (Beaudoin and Valberg 2017). Less than $0.2 \%$ of equine deaths under one year of age are attributed to digestive problems, including diarrhea potentially caused by salmonellosis (APHIS 2017). Deaths associated with salmonellosis are less likely in horses over one year of age.

Clostridium botulinum produces a toxin that causes botulism in horses. It results in progressive paralysis and is fatal in more than $80 \%$ of cases (Lenz 2016). Horses are more susceptible to botulism than cattle. It is most often associated with feed that has become wet and fermented or contaminated by dead animals. In most cases, CGMPs can be implemented to ensure feed stays dry. Pests such as rodents, birds, and flies are not considered biological hazards, but they can serve as vectors to introduce biological hazards like Clostridium botulinum. A pest management program should be part of the facility's CGMPs to mitigate the risk associated with these hazards.

\section{What are common chemical hazards to consider?}

Chemical hazards affecting horse feeds are more numerous and complex than physical and biological hazards. As with other hazards, the risks of chemical hazards are unique to each facility. Chemical hazards in horse feeds can be broken down into three categories: naturally occurring, unintentionally introduced, and intentionally introduced. While this is not a comprehensive list of all the chemical hazards that may occur, this section will attempt to highlight the major chemical hazards associated with horse feeds. It is important to recognize that chemical hazards that could affect horse feeds vary widely and must be detected through a thorough hazard analysis.

\section{Naturally Occurring}

Mycotoxins are the most common naturally occurring chemical hazard in horse feeds. While molds are considered biological systems, the mycotoxins produced by certain molds are classified as chemical hazards. There are several different kinds of mycotoxins. Severity depends the mycotoxin concentration and the animal consuming it. Aflatoxin and fumonisin are two mycotoxins of concern to horses.

Aflatoxins are mycotoxins that cause the most concern due to their high frequency and severe health effects. Aflatoxins are poisonous by-products of the mold fungus Aspergillus, which are found in crops such as corn and cottonseed that are used as feedstuffs for livestock. Dry and hot climates result in corn prone to a much higher risk of aflatoxin contamination (Medina, Rodriguez, and Magan 2014). The frequency of contamination usually depends on weather conditions. Close attention should be paid to the source of grain and grain by-products. Monitoring the weather in the region where feedstuffs are being sourced can be used as a SOP to determine the likelihood of aflatoxin contamination and trigger other SOPs or preventive control measures to mitigate risk. Due to the high incidence of aflatoxins in agricultural crops and health consequences from consumption of toxic levels, the FDA has set a default action level for aflatoxins of 20 parts per billion (ppb) with few exceptions. Horses are not one of those exceptions; therefore, horse feeds should meet this specified action level (FDA 2015a).

Fumonisin is a mycotoxin to which horses are particularly sensitive compared to other livestock species. It is produced by Fusarium molds that grow in warm climates under drought conditions, much like aflatoxins, and is typically associated with corn. There are the three subtypes of fumonisin: $\mathrm{B}_{1}, \mathrm{~B}_{2}$, and $\mathrm{B}_{3}$. Fumonisin $\mathrm{B}_{1}$ is the causative agent for equine leukoencephalomalacia and can lead to hepatotoxic syndrome (Caloni and Cortinovis 2010). The FDA recommends a maximum Fumonisin $B_{1}+B_{2}$ of less than 5 parts per million (ppm) (FDA 2001).

Undeclared allergens are a leading cause of recalls for human food (FDA 2016), yet allergens are not considered a serious hazard in horse feed. Generally, allergies may manifest themselves as dermatitis in horses rather than the severe allergic reaction observed in humans. No serious adverse health consequences of allergens in horse feed have been reported to the Reportable Food Registry from 2009-2014 (FDA 2016).

\section{Unintentionally Introduced}

Unintentionally introduced chemical hazards in horse feeds are of relatively low frequency, but the implications can be severe in some cases. Examples of unintentionally introduced chemical hazards include but are not limited to 
pesticides and other chemical residues, drug carryover, and toxic substances.

Since pesticides and other chemicals are applied to many crops used for horse feedstuffs to ensure proper yields, residues may be present. The FDA Pesticide Monitoring Program suggests that very few animal feeds contain levels that exceed permitted levels. Only $1.9 \%$ of 366 animal feed samples were reported in violation of EPA tolerance or FDA action levels during the 2014 fiscal year (FDA 2017).

The harvesting process and the manufacturing environment expose feedstuffs to possible contamination by petroleumbased greases and other chemicals. These residues can pose risks to animals due to the accumulation of these products in fat tissues. In most cases, CGMPs and SOPs for handling and storage of greases and other chemicals mitigate the risk. A transition to food-grade greases may also be a solution.

Drug carryover can be a concern. However, facilities should already have CGMPs in place to manage medicated feeds (FDA HHS 2014). It is also important to note that feed additives containing medically important antimicrobials may fall under the Veterinary Feed Directive (VFD). The VFD brings therapeutic uses of drugs under veterinary supervision and requires a prescription to use medically important drugs in feed or water of food-producing animals. For more information on feed additives that may fall under the VFD, refer to the FDA's website on the Veterinary Feed Directive (FDA 2015b).

Ionophores are commonly used as coccidiostats in cattle and poultry. They include compounds like monensin (Rumensin ${ }^{\circledR}$, Elanco), lasalocid (Bovatec ${ }^{\oplus}$, Zoetis), laidlomycin (Cattlyst ${ }^{\circledast}$, Zoetis), narasin (Maxiban ${ }^{\circledR}$, Elanco), and salinomycin. However, horses are extremely sensitive to ionophores. Consumption of toxic levels can lead to chronic heart failure and sudden death (Bautista et al. 2014; Decloedt et al. 2012). Monensin has a fatal dose of 4.4-6.6 mg per pound of body weight. While the frequency of death associated with ionophore toxicity is low (APHIS 2017), the severe consequences of manufacturer error warrant robust procedures to ensure ionophores are not accidentally included in horse feed, particularly in facilities that supply multiple species. These procedures may include, but are not limited to, batching and sequencing protocols with appropriate flushing prior to mixing feed intended for horses. These are similar CGMPs that facilities may already have in place for medicated feeds (FDA HHS 2014).

\section{Intentionally Introduced}

Intentionally introduced chemical hazards can be any of the aforementioned hazards that are introduced to feedstuffs for economic gain or sabotage. The most well-known example of a chemical hazard that was intentionally introduced for economic gain is melamine in pet foods. Melamine was used to artificially inflate the measured protein content of wheat gluten and rice protein concentrate, but it led to kidney failure in dogs and cats that consumed it in their food. Intentionally introduced hazards are difficult to predict and should be considered when reviewing CGMPs and SOPs to attempt to mitigate the risks.

\section{What are common physical hazards to consider?}

Physical hazards can include stones, glass, metal, wood, plastic, or any physical object that could enter the feed and cause harm, perhaps through choking or laceration. During the harvest, grinding, mixing, or other processing of feed, it is possible for metal from the equipment to break and become introduced into the feed. A poorly located and unprotected light bulb has risk of shattering. Tools, cell phones, glasses, and other objects may be misplaced or fall into processing equipment and become physical hazards in the feed.

A physical hazard's frequency and severity depend on each facility and process. A facility might choose to utilize a magnet or a screen to remove contaminants as part of its SOPs to reduce the frequency of the hazard. In addition, shatterproof bulbs can be strategically located to reduce the risk of glass contamination. SOPs for handling tools and personal effects can mitigate the risk of those objects becoming physical hazards. Each facility should take into account the source of ingredients, product flow, equipment, packaging, and storage to determine points where physical hazards could enter the product and determine appropriate measures to prevent them.

\section{How do I prevent these hazards from occurring?}

There are multiple ways of preventing hazards from occurring in horse feeds. All employees should be trained to do their respective jobs and be knowledgeable about basic feed safety. Appropriate methods of prevention are usually dependent upon each hazard, its severity, and its likelihood of occurring. Robust CGMPs and SOPs are usually already in practice in most facilities; they just need to be reviewed and revised to ensure they are effective in controlling 
potential hazards. However, there are some hazards that may require more intense methods of prevention due to their severity or frequencies.

Some facilities elect to implement preventive controls. Preventive controls are additional actions taken to ensure the prevention of certain hazards and increase accountability through required monitoring, verification, validation, and record keeping components where appropriate. There are four forms of preventive controls: process controls, sanitation controls, supply-chain or supplier controls, and other controls. Process controls are the most likely to be used. These could include batching and sequencing procedures and ingredient use reconciliation.

The decision to use CGMPs and SOPs or preventive controls to control hazards is dependent on each facility and hazard. Be aware that decisions regarding methods of prevention require justification. Justification should be based on facility experience, illness data, scientific reports, and FDA resources. In addition, justification should be documented. It should also provide a thorough explanation of the decision.

\section{Conclusion}

A critical component of a food safety plan required under FSMA is the hazard analysis. A thorough assessment of potential hazards is important to determine if current practices are sufficient to produce safe animal feed.

Horses are uniquely sensitive to fumonisin and ionophores compared to other livestock species. Facilities, particularly mixed-species feed facilities, need to ensure CGMPs, SOPs, and possibly preventive controls are implemented to address those concerns in addition to more general hazards.

\section{Additional Information}

FDA (key requirements for preventive controls for animal feed): http://www.fda.gov/downloads/Food/GuidanceRegulation/FSMA/UCM461884.pdf

FDA (FSMA; animal feed overview): http://www.fda. gov/AnimalVeterinary/Products/AnimalFoodFeeds/ ucm347941.htm

UF/IFAS Department of Animal Sciences (FSMA): http:// animal.ifas.ufl.edu/FSMA/index.shtml

Food Safety Preventive Controls Alliance (FSPCA): https:// www.ifsh.iit.edu/fspca

\section{References}

APHIS. 2017. "Equine mortality in the United States, 2015." United States Department of Agriculture, Animal and Plant Health Inspection Service. Accessed on October 27, 2017. http://www.aphis.usda.gov/animal_health/nahms/equine/ downloads/equine15/Equine15_is_Mortality.pdf

Bautista, A. C., J. Tahara, A. Mete, C. L. Gaskill, U. K. Bryant, and B. Puschner. 2014. "Diagnostic value of tissue monensin concentrations in horses following toxicosis." Journal of Veterinary Investigation 26(3): 423-427.

Beaudoin, A. and S. Valberg. 2017. "Salmonella in horses." University of Minnesota Extension. Accessed on October 27, 2017. https://www.extension.umn.edu/agriculture/horse/ health/salmonella-in-horses/

Caloni, F. and C. Cortinovis. 2010. "Effects of fusariotoxins in the equine species." The Veterinary Journal 186(2):

157-161. https://doi.org/10.1016/j.tvjl.2009.09.020

Decloedt, A., T. Verheyen, D. De Clercq, S. Sys, G. Vercauteren, R. Ducatelle, P. Delahaut, and G. van Loon. 2012. "Acute and long-term cardiomyopathy and delayed neurotoxicity after accidental lasalocid poisoning in horses." Journal of Veterinary Internal Medicine 26(4): 1005-1011. doi: 10.1111/j.1939-1676.2012.00933.x.

FDA. 2017. "Pesticide Residue Monitoring Program: Fiscal Year 2014 Pesticide Report." U.S. Food \& Drug Administration. Accessed on October 19, 2017. https://www.fda. gov/downloads/Food/FoodborneIllnessContaminants/ Pesticides/UCM546325.pdf

FDA. 2015a. "Compliance Policy Guide Sec. 683.100 Action levels for aflatoxins in animal feeds." U.S. Food \& Drug Administration. Accessed on October 29, 2017. https:// www.fda.gov/ICECI/ComplianceManuals/CompliancePolicyGuidanceManual/ucm074703.htm

FDA. 2015b. "Veterinary Feed Directive (VFD)." U.S. Food \& Drug Administration. Accessed on November 19, 2017. https://www.fda.gov/animalveterinary/developmentapprovalprocess/ucm071807.htm

FDA. 2013. "Compliance Policy Guide Sec. 690.800 Salmonella in food for animals." Food and Drug Administration. Accessed on October 28, 2017. https://www.fda.gov/ downloads/ICECI/ComplianceManuals/CompliancePolicyGuidanceManual/UCM361105.pdf 
FDA. 2001. "Guidance for industry: Fumonisin levels in human foods and animal feeds." U.S. Food \& Drug Administration. Accessed on November 3, 2017. https://www.fda. gov/Food/GuidanceRegulation/GuidanceDocumentsRegulatoryInformation/ChemicalContaminantsMetalsNaturalToxinsPesticides/ucm109231.htm

FDA. 2016. “The Reportable Food Registry: A five year overview of targeting inspection resources and identifying patterns of adulteration-September 8, 2009-September 7, 2014." U.S. Food and Drug Administration. Accessed on October 26, 2017. http://www.fda.gov/downloads/Food/ ComplianceEnforcement/RFR/UCM502117.pdf

FDA HHS. 2014. “21 CFR $\$ 225$. Current good manufacturing practice for medicated feeds." Federal Register. Accessed on October 19, 2017. https://www. federalregister.gov/documents/2014/01/23/2014-01299/ current-good-manufacturing-practice-for-medicated-feeds

Leedom-Larson, K. R. and A. R. Spickler. 2013. "Salmonellosis." Accessed on October 27, 2017. http://www.cfsph. iastate.edu/Factsheets/pdfs/nontyphoidal_salmonellosis.pdf

Lenz, T. 2016. "Equine botulism." American Association of Equine Practitioners. Accessed on November 19, 2017. https://aaep.org/horsehealth/equine-botulism

Li, X., L. A. Bethune, Y. Jia, R. A. Lovell, T. A. Proescholdt, S. A. Benz, T. C. Schell, G. Kaplan, and D. G. McChesney. 2012. "Surveillance of Salmonella prevalence in animal feeds and characterization of the Salmonella isolates by serotyping and antimicrobial susceptibility." Foodborne Pathogens and Disease 9(8): 692-698. doi: 10.1089/ fpd.2011.1083

Medina, A., A. Rodriguez, and N. Magan. 2014. "Effect of climate change on Aspergillus flavus and aflatoxin $\mathrm{B}_{1}$ production." Frontiers in Microbiology 5: 348. doi: 10.3389/ fmicb.2014.00348

Scheffler, J. M. and C. Carr. 2016. The Food Safety Modernization Act (FSMA) Preventive Controls for Animal Food. AN330. Gainesville: University of Florida Institute of Food and Agricultural Sciences. http://edis.ifas.ufl.edu/an330 